\title{
Comparison of the Effect of Surface Conditioning Methods on the Bond Strength of Different Zirconia Reinforced Lithium Silicate and Hybrid Ceramics to Resin Cement
}

\author{
Hatice Sevmez ${ }^{1}$, Handan Yilmaz ${ }^{1} \mathbb{D}$ \\ ${ }^{1}$ Department of Prosthodontics, Faculty of Dentistry, Gazi University, Ankara, Turkey \\ Correspondence Author: Handan Yilmaz \\ E-mail: hozkula@gmail.com \\ Received: 25.01 .2021 \\ Accepted: 07.07 .2021
}

\begin{abstract}
Objective: The objective of this study is to investigate the effect of surface treatment techniques on the shear bond strength (SBS) of resin cement bonded to CAD / CAM materials.

Methods: The zirconia-reinforced lithium silicate, Vita Suprinity (VS) and Celtra Duo (CD), and hybrid ceramics, Vita Enamic (VE) and Nacera Hybrid $(\mathrm{NH})$, were used. Eighty specimens from each material were fabricated following the manufacturer's instructions and separated into 8 groups according to surface treatments. These were; K (control, no treatments), H (hydrofluoric acid), HS (H+ Silane S), A (abraded with 50-micron alumina particles $A$ ), AS ( $A+S), C$ (abraded with 30-micron Cojet sand $C$ ), $C S(C+S), S$. The mean surface roughness (SR) of the specimens was evaluated. Surface treated specimens were cemented to the resin cement (Panavia F 2.0) for testing the adhesion using the shear bond strength (SBS) test. Mean SR and SBS were evaluated by 2-way ANOVA with the material type and surface treatments techniques as the independent factors.

Results: A and AS groups were observed to have the highest SR values. Both hybrid ceramics VE and NH showed the highest SR values among surface treatments. The highest SBS values were found usually on the H and HS treated surfaces. The highest values were observed on the CD material in the HS group (18.01MPa) and followed by the VE material (16.25 MPa) in the CS group. For CD and VS materials, adhesive and cohesive failures were found; and for VE and NH materials, adhesive and mixed cohesive failures were observed.
\end{abstract}

Conclusion: The surface treatment showed a significant effect on SR and SBS values. Although the SR values of the materials are high in the A and AS group, the highest SBS values were observed on $\mathrm{H}$ and $\mathrm{HS}$ treated surfaces.

Keywords: Shear Bond Strength, Surface Roughness, Hybrid Ceramic, Zirconia Reinforced Lithium Silicate Ceramic.

\section{INTRODUCTION}

Ceramics and resin-based composites are two different types of dental materials (1). Ceramics have good mechanical and optical properties and excellent biocompatibility due to their chemical stability (2). New ceramic materials in dentistry are increasing as stronger and tougher materials are developed with contemporary manufacturing techniques $(3,4)$. These include monolithic zirconia, zirconia reinforced lithium silicate ceramics and hybrid ceramics $(3,5,6)$. Monolithic restorations have significant advantages such as decreased manufacturing time, improved cost effectiveness and elimination of the interface between the core and veneer materials $(7,8)$. Recently various monolithic glass ceramic materials also come into use currently with CAD/CAM systems for the application of fixed prosthesis $(5,9)$. This new zirconia reinforced lithium silicate glass ceramics are enriched lithium silicate glass ceramics ( $10 \%$ by weight) and combine the favorable material properties of zirconia $\left(\mathrm{ZrO}_{2}\right)$ and glass ceramic. The zirconia particles were added to reinforce the ceramic structure. $(9,10,11,12)$.
Hybrid ceramics introduced to the market to achieve a material with elastic modulus comparable to dentin have a number of advantages, including less crack propagation and better fracture resistance than few CAD / CAM systems (1, 6, $11,13,14,15)$. Hybrid ceramics are composites of nanofiller and resins $(6,11,16,17)$. These materials composed of an organic polymer matrix reinforced by inorganic filler particles consist of porcelain glasses and ceramics (6).

The fracture resistance of ceramic materials can also be reinforced by the properties of the support materials or the bond strength. It was described that well-cemented specimens were generally more fracture resistant (13). For long term success, adhesion to a ceramic material is the one of the most important properties to evaluate the bond durability $(14,19)$. Another key factor for the clinical success of fixed prosthesis is the cementation procedure $(20,21)$. Luting cements and agents link prosthetic restorations with the supporting tooth structure and interfacial surface defects $(13,19,20,21)$. Retention loss 
is the second reason why traditional fixed prostheses fail (21). Usually, ceramic restorations are pretreated physically or chemically, but are more likely made by a combination of both methods (22). The strength of the adhesion between the ceramic and the bonding agent determines the clinical success of a ceramic restoration. Also, clinical success partially depends on the adhesion techniques controlled by the surface treatments used (23). Various conditioning methods for ceramic surface pretreatment such as roughening the surface with a diamond bur, sandblasting with alumina or silica-coated alumina oxide particles, chemical etching with hydrofluoric acid (HF) are recommended to increase adhesion $(4,20,23)$

Acid abrasion resistant ceramics require some special surface treatment to optimize bonding to the resin-based composite. The most common surface treatments for this purpose are airborne particle abrasion and silica coating. (22). Air particle abrasion is also used to increase the roughness of the ceramic. Surface roughness (SR) allows interlocking between ceramic and resin cement. $(24,25)$. Ceramics with high glass content form a micro mechanical retention surface as a result of the effect of $\mathrm{HF}$, and these ceramics are called acid-sensitive (12). During HF etching, some parts of the silicate ceramic surface are removed and a surface roughness occurs $(4,22)$. Application of silane coating agent is a chemical approach to bonding to ceramic and provides a chemical connection between ceramic and resin composite $(4,12,22)$. These agents can create chemical connections between the inorganic phase of the ceramic and the organic phase of the resin $(26,27)$.

Fracture resistance of the ceramic-resin adhesion is controlled by the microstructure and surface treatment (28). Mechanical laboratory tests can be used to show material selection and clinical recommendations for resin bonding to ceramics. $(4,19)$. Various methods can be used for the assessment of the bond strength: 3-point bending, the tensile and micro tensile and the shear and micro shear tests $(4,19,28)$. The most common method is the shear bond strength (SBS) test $(4,17,28,29)$. The advantages of the shear bond strength (SBS) test performed by applying parallel force to the binding interface are easy specimen preparation and simple test protocol. $(14,16,17,19$, $30,31)$. Nevertheless, non-uniform stress distribution in the bonding surface and polymerization shrinkage of resin cement are not considered in this technique $(28,29,30)$.

The objective of this study is to evaluate the effect of different surface treatments on surface roughness and shear bond strength of resin cement bonded to different ceramic materials. The null hypothesis in this study is that surface roughness and SBS are not affected by material variety and surface treatment technique.

\section{METHODS}

Two zirconia reinforced lithium silicate ceramics, Vita Suprinity (VS) and Celtra Duo (CD) and two hybrid ceramics, Vita Enamic (VE) and Nacera Hybrid (NH) were selected for the study. The materials, their manufacturers and compositions used in this study are shown in Table 1 . All specimens $(10 \times 10 \times 1 \mathrm{~mm})$ in this study were prepared from prefabricated blocks. 320 specimens were separated into 8 subgroups $(n=10)$ for various surface treatments to be applied. The schematic diagram of the experimental groups is shown in Figure 1.

Table 1. Composition of the materials tested in this study.

\begin{tabular}{|c|c|c|c|c|}
\hline Material & Brand & Manufacturer & Lot No & Composition \\
\hline $\begin{array}{l}\text { Zirconia-reinforced } \\
\text { Lithium Silicate }\end{array}$ & $\begin{array}{l}\text { Celtra Duo } \\
\text { CD }\end{array}$ & Sirona Dentsply, Milford, De, USA & 16000579 & $\begin{array}{l}\mathrm{SiO}_{2}, \mathrm{P}_{2} \mathrm{O}_{5}, \mathrm{Al}_{2} \mathrm{O}_{3}, \mathrm{Li}_{2} \mathrm{O}, \mathrm{ZnO}_{2}, \mathrm{~Tb}_{4} \mathrm{O}_{7}, \mathrm{ZrO}_{2}, \mathrm{CeO}_{2}, \\
\text { pigments }\end{array}$ \\
\hline $\begin{array}{l}\text { Zirconia-reinforced } \\
\text { Lithium Silicate }\end{array}$ & Vita VS Suprinity & $\begin{array}{l}\text { Vita Zahnfabrick, Bad Säckingen, } \\
\text { Germany }\end{array}$ & 59841 & $\begin{array}{l}\mathrm{ZrO}_{2^{\prime}} \mathrm{SiO}_{2^{\prime}} \mathrm{Li}_{2} \mathrm{O}, \mathrm{La}_{2} \mathrm{O}_{3}, \mathrm{P}_{2} \mathrm{O}_{5^{\prime}}, \mathrm{K}_{2} \mathrm{O}, \mathrm{Al}_{2} \mathrm{O}_{3^{\prime}}, \mathrm{La}_{2} \mathrm{O}_{3^{\prime}}, \mathrm{CeO}_{2^{\prime}} \\
\text { pigments }\end{array}$ \\
\hline $\begin{array}{l}\text { Hybrid } \\
\text { Ceramic }\end{array}$ & Vita VE Enamic & $\begin{array}{l}\text { Vita Zahnfabrik, Bad Säckingen, } \\
\text { Germany }\end{array}$ & 63460 & $\begin{array}{l}\mathrm{SiO}_{2}, \mathrm{Al}_{2} \mathrm{O}_{3}, \mathrm{Na}_{2} \mathrm{O}, \mathrm{K}_{2} \mathrm{O}, \mathrm{B}_{2} \mathrm{O}_{3}, \mathrm{CaO}, \mathrm{TiO}_{2}, \text { UDMA, } \\
\text { TEGDMA }\end{array}$ \\
\hline $\begin{array}{l}\text { Hybrid } \\
\text { Ceramic }\end{array}$ & Nacera NH Hybrid & $\begin{array}{l}\text { Doceram Medical Ceramics Gmbh, } \\
\text { Dortmund, } \\
\text { Germany }\end{array}$ & 230516 & $\begin{array}{l}50 \% \text { Nano-Glass, } \\
50 \% \text { Polymer-Matrix }\end{array}$ \\
\hline Hydrofluoric Acid & $\begin{array}{l}\text { IPS Ceramic Etching } \\
\text { Gel }\end{array}$ & Ivoclar Vivadent, Schaan, Lichtenstein & W31655 & $<\% 5$ Hydrofluoric Acid \\
\hline Aluminium Oxide Sand & Korox & $\begin{array}{l}\text { Bego, Bremen, } \\
\text { Germany }\end{array}$ & $\begin{array}{l}143617811 \\
12\end{array}$ & $\% 99.6 \mathrm{Al}_{2} \mathrm{O}_{3}(50 \mu \mathrm{m})$ \\
\hline Cojet Sand & Cojet Sand & $\begin{array}{l}\text { 3M ESPE, St. Paul, } \\
\text { USA }\end{array}$ & 654604 & $30 \mu \mathrm{m}$ silica coated sand \\
\hline Silane Coupling Agent & Monobond N Silane & Ivoclar Vivadent, Schaan, Lichtenstein & W90335 & $\begin{array}{l}\text { Alcohol based silane metacrylate, Phosphoric } \\
\text { Acid Methacrylate, Sulfur Methacrylate Solution }\end{array}$ \\
\hline \multirow[t]{2}{*}{ Dual Cure Resin Cement } & \multirow[t]{2}{*}{ Panavia F 2.0} & \multirow[t]{2}{*}{ Kuraray Medical Inc., Okayama, Japan } & B70150 & $\begin{array}{l}\text { Paste A: MDP, hydrophobic aromatic and aliphatic } \\
\text { photoiniator, dibenzoyl peroxide dimethacrylate, } \\
\text { hydrophilic dimetacrylate, silanized silica, } \\
\text { silanized colloidal silica, camphorquinone, } \\
\text { catalysts, initiators }\end{array}$ \\
\hline & & & AR0034 & $\begin{array}{l}\text { Paste B: Hydrophobic aromatic and aliphatic } \\
\text { dimethacrylate, silanized barium glass, sodium } \\
\text { fluoride, catalysts, initiators, color pigments. }\end{array}$ \\
\hline
\end{tabular}




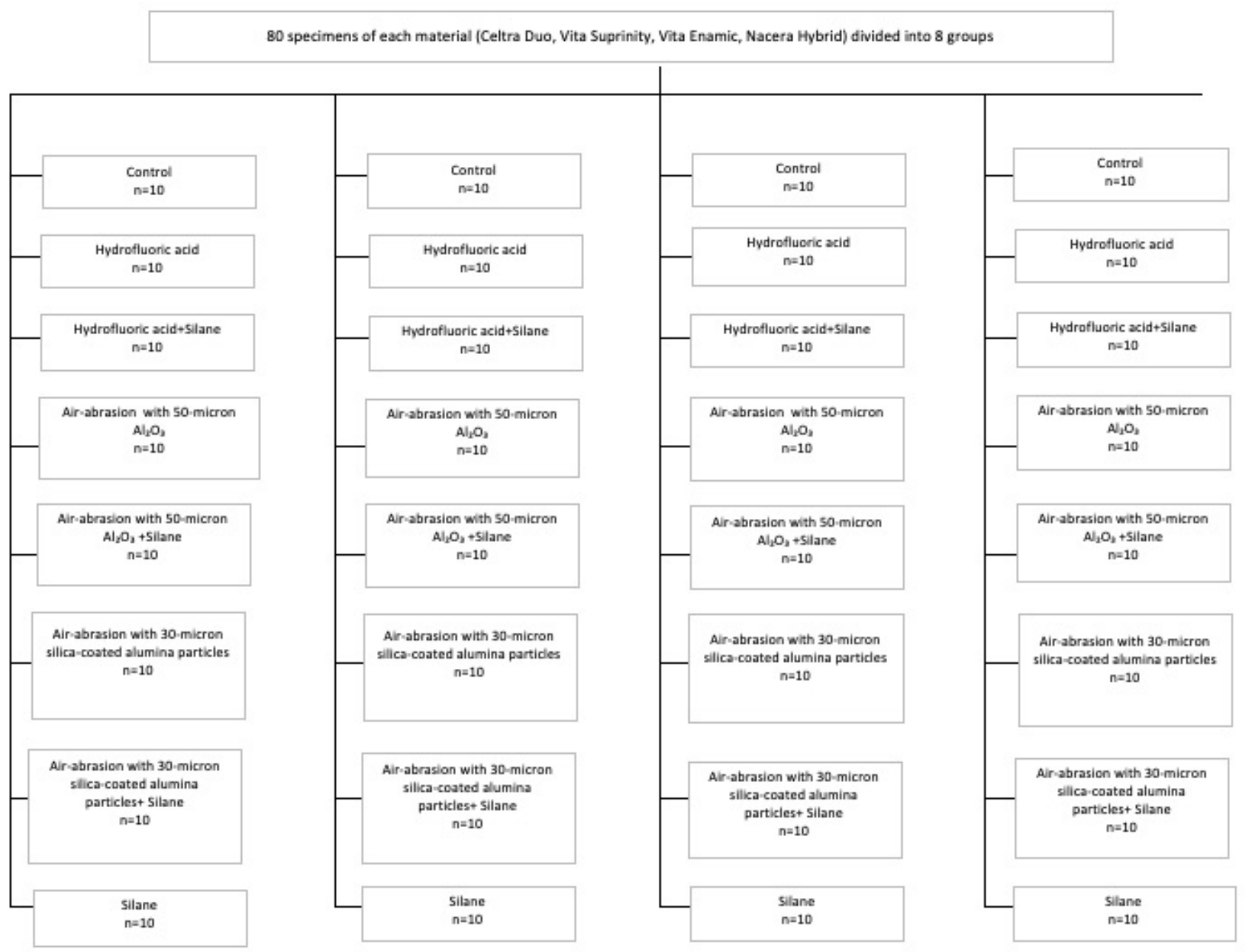

Figure 1. Schematic diagram of experimental groups.

All specimens were put into acrylic resin blocks and then polished under water cooling to obtain standardized surfaces. The specimens were separated into 8 groups according to the used surface treatments.

K: No treatment (control)

$\mathrm{H}$ : \%5 Hydrofluoric acid application for 20 seconds

HS: \%5 HF acid for 20 seconds + silane application for 60 seconds.

A: Air-abrasion with 50 -micron $\mathrm{Al}_{2} \mathrm{O}_{3}$ at 2-5 bar pressure.

AS: Air-abrasion with 50-micron particles of alumina $\mathrm{Al}_{2} \mathrm{O}_{3}$ at 2.5 bar pressure + silane application for 60 seconds.

C: Air-abrasion with 30-micron silica-coated alumina particles with 2.5 bar pressure.

CS: Air-abrasion with 30-micron silica-coated alumina particles with 2.5 bar pressure + silane application for 60 seconds.

\section{S: Silane application for 60 seconds.}

All specimens were cleaned with ethanol and distilled water for 10 minutes in an ultrasonic cleaner after all surface treatments. A surface roughness (SR) profile was determined for each group using a profilometer (Mahr Surf M 300c,
Mahr Gmbh, Germany). Three readings were taken from the surface of the specimens and a mean value was calculated.

After SR measurements, a dual-cure resin cement (Panavia F 2.0, Kuraray Medical Inc, Japan) was packed onto specimen surfaces using a mold which was $3 \mathrm{~mm}$ in diameter and $2 \mathrm{~mm}$ in depth cylindrical. Layers were added incrementally and cured using a lightcuring unit (BA Optima 10 Boses 20, BA International Ltd. England). The application of cement in the specimen is shown in Figure 2. Then all specimens were kept in $37^{\circ} \mathrm{C}$ distilled water for 24 hours.

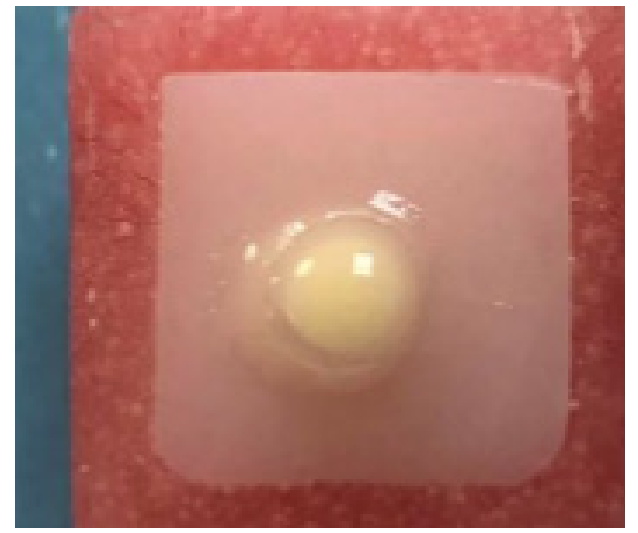

Figure 2. The application of dual-cure resin cement on the specimen. 
The SBS was determined with a universal testing machine (Lloyd Instruments, Ametek Inc. Florida USA). SBS test with specimens is shown in Figure 3. The specimens were loaded at a crosshead speed of $0.5 \mathrm{~mm} / \mathrm{min}$. The maximum load $(P)$ was measured when the resin cement was separated from the specimen. The SBS was measured from the formula below:

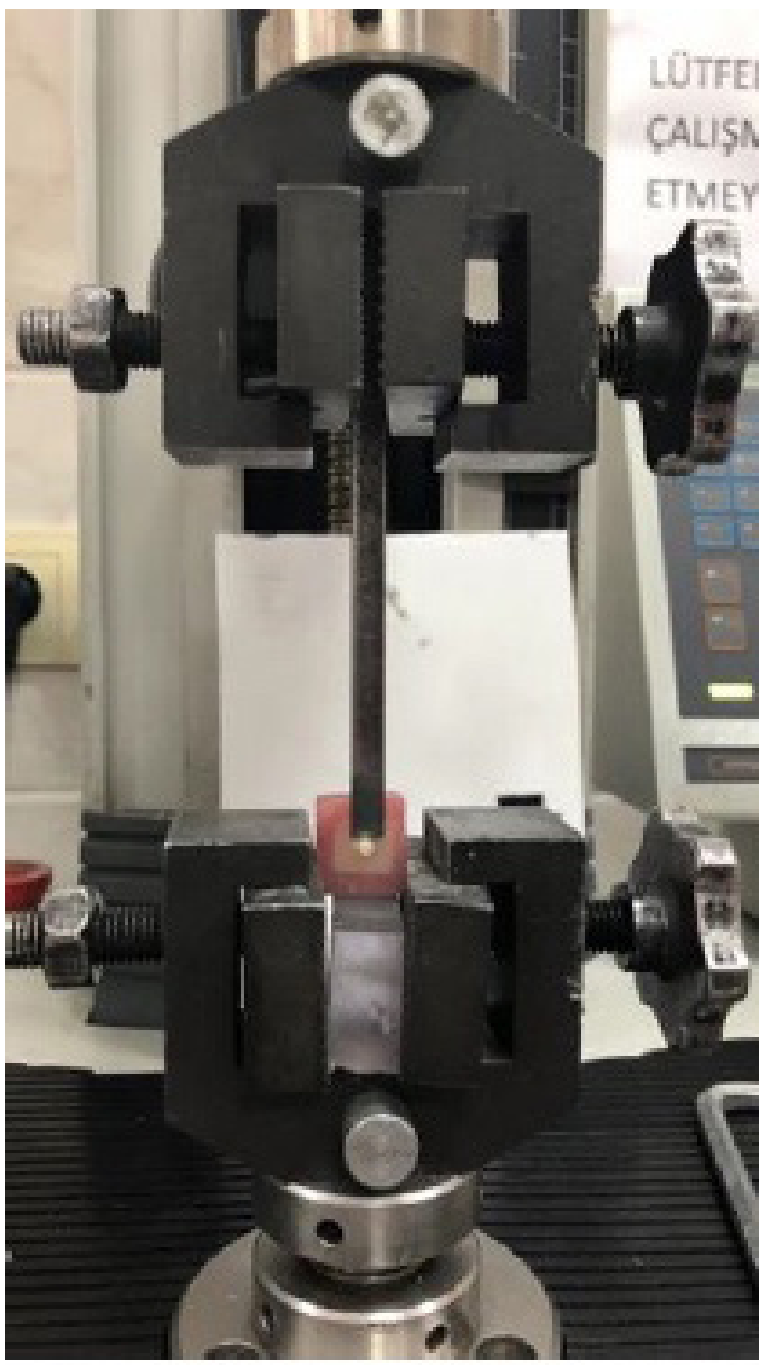

Figure 3. The specimen under the SBS test in the universal testing machine.

SBS (in MPa): $\mathrm{P} \times 9.8 / r^{2} \times \pi$,

where is the maximum load (in $\mathrm{kg} \mathrm{F}$ ) and $r$ is the radius (in $\mathrm{mm}$ ) of the resin cement.

After the SBS test, the interface of the specimens was analyzed using a loupe (Loupe opt-on Orange Dental, Biberach Germany) at $2.5 \mathrm{~mm}$ magnification. The fracture modes were classified as follows:

Type 1: Adhesive (between the surface of the both materials),

Type 2: Cohesive (within the ceramic material),

Type 3: Cohesive (failure within the material and resin cement) failure.
Statistical analyses were applied to the surface roughness and SBS values. Mean surface roughness and SBS results analyzed 2-way ANOVA with the material type and surface treatments as the independent variables. Multiple comparisons were made by Tukey's and Tamhane's tests. Statistical significance was set at the 0.05 probability level. The correlation between SR and SBS results was investigated using Pearson correlation and chi-squared analysis.

\section{RESULTS}

\subsection{Surface Roughness}

Multiple comparisons of the mean SR values of the materials used in this study and surface treatment methods were made with Tukey's and Tamhane's test.

Table 2. Mean and standart deviation (SD) of the surface roughness (Ra) values for the materials used in this study.

\begin{tabular}{|c|c|c|c|c|c|c|}
\hline \multirow{2}{*}{ Materials } & \multirow{2}{*}{$\begin{array}{l}\text { Surface } \\
\text { Treatments }\end{array}$} & \multicolumn{3}{|c|}{ Ra Values } & \multicolumn{2}{|c|}{ One-Way ANOVA } \\
\hline & & $\mathrm{n}$ & Mean & SD & $\mathrm{F}$ & $p$ \\
\hline \multirow{8}{*}{ CD } & K & 10 & $0.19^{d}$ & 0.06 & \multirow{8}{*}{116.58} & \multirow{8}{*}{0.001} \\
\hline & H & 10 & $0.35^{c}$ & 0.08 & & \\
\hline & HS & 10 & $0.37^{c}$ & 0.11 & & \\
\hline & A & 10 & $1.65^{a}$ & 0.26 & & \\
\hline & AS & 10 & $1.45^{\text {a.e }}$ & 0.34 & & \\
\hline & C & 10 & $1.15^{b, e}$ & 0.11 & & \\
\hline & CS & 10 & $0.96^{b}$ & 0.14 & & \\
\hline & $S$ & 10 & $0.18^{d}$ & 0.04 & & \\
\hline \multirow{8}{*}{ VS } & K & 10 & $0.18^{c}$ & 0.05 & \multirow{8}{*}{125.152} & \multirow{8}{*}{0.001} \\
\hline & $\mathrm{H}$ & 10 & $0.2^{c}$ & 0.07 & & \\
\hline & HS & 10 & $0.15^{c, d}$ & 0.07 & & \\
\hline & A & 10 & $1.5^{\mathrm{a}}$ & 0.31 & & \\
\hline & AS & 10 & $1.39^{a}$ & 0.29 & & \\
\hline & C & 10 & $0.92^{b}$ & 0.13 & & \\
\hline & CS & 10 & $0.95^{b}$ & 0.1 & & \\
\hline & $S$ & 10 & $0.09^{d}$ & 0.03 & & \\
\hline \multirow{8}{*}{ VE } & $K$ & 10 & $0.18^{d}$ & 0.04 & \multirow{8}{*}{170.055} & \multirow{8}{*}{0.001} \\
\hline & $\mathrm{H}$ & 10 & $0.39^{c}$ & 0.05 & & \\
\hline & HS & 10 & $0.37^{c}$ & 0.04 & & \\
\hline & A & 10 & $1.82^{\mathrm{a}}$ & 0.19 & & \\
\hline & AS & 10 & $1.79 \mathrm{a}, \mathrm{e}$ & 0.38 & & \\
\hline & C & 10 & $1.21^{b}$ & 0.17 & & \\
\hline & CS & 10 & $1.31^{b, e}$ & 0.13 & & \\
\hline & $s$ & 10 & $0.18^{d}$ & 0.06 & & \\
\hline \multirow{8}{*}{ NH } & $K$ & 10 & $0.23^{c}$ & 0.08 & \multirow{8}{*}{384.525} & \multirow{8}{*}{0.001} \\
\hline & $\mathrm{H}$ & 10 & $0.22^{c}$ & 0.07 & & \\
\hline & HS & 10 & $0.19^{c}$ & 0.04 & & \\
\hline & A & 10 & $2.18^{a}$ & 0.24 & & \\
\hline & AS & 10 & $1.96^{\mathrm{a}}$ & 0.2 & & \\
\hline & $C$ & 10 & $1.43^{b}$ & 0.11 & & \\
\hline & CS & 10 & $1.34^{b}$ & 0.18 & & \\
\hline & $S$ & 10 & $0.21^{c}$ & 0.05 & & \\
\hline
\end{tabular}

*Tukey HSD test, Tamhane's test. There is no statistically significant difference between the mean Ra values of the groups with common lowercase letters ( $p>0.05$ ) 
The mean SR values of the materials used and surface treatments are presented in Table 2. The SR was affected significantly differently from the treatments for all materials, and the effect of surface treatment methods was evaluated for each material. Within all materials, the highest SR values were observed in the $A$ and then AS group and the value difference between the two groups was not significant $(p>0.05)$. The Mean values of A groups were; $1.65 \pm 0.26 \mathrm{MPa}$ for $C D, 1.5 \pm 0.31 \mathrm{MPa}$ for $\mathrm{VS}, 1.82 \pm 0.19 \mathrm{MPa}$ for $\mathrm{VE}, 2.18 \pm 0.24$ $\mathrm{MPa}$ for $\mathrm{NH}$. The mean values of AS groups were; $1.45 \pm 0.34$ $\mathrm{MPa}$ for $\mathrm{CD}, 1.39 \pm 0.29 \mathrm{MPa}$ for $\mathrm{VS}, 1.79 \pm 0.38 \mathrm{MPa}$ for $\mathrm{VE}$, $1.96 \pm 0.2 \mathrm{MPa}$ for $\mathrm{NH}$. Then, $\mathrm{C}$ and $\mathrm{CS}$ groups significantly followed these two groups. The lowest Ra values were found generally in $\mathrm{K}$ and $\mathrm{S}$ groups for all materials. Among the surface treatment groups, the highest Ra values were observed in the A group on $\mathrm{NH}$ material, in the $\mathrm{C}$ group on the VE material, and in AS and CS groups on NH and VE materials. Then, the lowest Ra values were obtained in $\mathrm{H}$ and $\mathrm{HS}$ groups in $\mathrm{NH}$ and VS materials.

\subsection{Shear Bond Strength}

Multiple comparisons of the mean SBS values and surface treatment methods were made with Tukey's tests. The mean shear bond strength test values of the materials used and surface treatments are presented in Table 3. The SBS test values were significantly affected by surface treatment methods for all materials and the effect of the treatments was evaluated for each material. Within all the materials used, the highest SBS test values were observed in $\mathrm{H}$ and $\mathrm{HS}$ groups on $\mathrm{CD}, \mathrm{VS}, \mathrm{NH}$ materials and in the $\mathrm{CS}$ group on the VE material (16.25 $\pm 5.83 \mathrm{MPa})$. CD material mean values are; $11.58 \pm 2.53 \mathrm{MPa}$ for $\mathrm{H}$ group, $18.01 \pm 4.07 \mathrm{MPa}$ for HS group. VS material mean values are; $18.84 \pm 4.37 \mathrm{MPa}$ for $\mathrm{H}$ group, $11.60 \pm 3.09 \mathrm{MPa}$ for HS group. NH material mean values are; $12.81 \pm 4.03 \mathrm{MPa}$ for $\mathrm{H}$ group, $12.44 \pm 3.43 \mathrm{MPa}$ for HS group. The lowest SBS values were generally found in the control group. Among the surface treatment groups, the highest SBS values were observed in C and CS groups on the VE material, and in A and AS groups on VE and VS materials. The lowest SBS test value was found in the $\mathrm{K}$ group at the CD material.

After the SBS test, the interface of the fracture specimens was analyzed and the fracture mode was classified as presented in Table 4. The failure type on the surfaces of all used materials differed according the material type and the surface treatments. Among the tested materials, when all surface treatments were evaluated, the Type 1 highest adhesive failure was observed in $\mathrm{NH}$ and then $\mathrm{CD}$ material, Type 2 cohesive failure was seen in VS and then CD materials and Type 3 cohesive failure was primarily seen in VE material. Type 3 cohesive failure was not observed in CD and VS materials. Among the surface treatments, when all tested materials were evaluated, the highest Type 1 adhesive failure was observed in $\mathrm{K}$ and $\mathrm{S}$ treatment groups, Type 2 cohesive failure was seen in CS and then HS groups and Type 3 cohesive failure was observed primarily in HS treatment group. Type 3 cohesive failure was not observed in $\mathrm{K}$ and $\mathrm{S}$ groups.

Table 3. Mean and standart deviation (SD) of the Shear Bond Strength (SBS) (MPa) values of the materials used.

\begin{tabular}{|c|c|c|c|c|c|c|}
\hline \multirow[t]{2}{*}{ Materials } & \multirow[t]{2}{*}{ Surface Treatments } & \multicolumn{3}{|c|}{ SBS Values } & \multicolumn{2}{|c|}{$\begin{array}{c}\text { One-Way } \\
\text { ANOVA }\end{array}$} \\
\hline & & n & Mean & SD & $\mathbf{F}$ & $p$ \\
\hline \multirow{8}{*}{ CD } & K & 10 & $2.45^{\mathrm{e}}$ & 1.56 & \multirow{8}{*}{33.924} & \multirow{8}{*}{0.001} \\
\hline & $\mathrm{H}$ & 10 & $11.58^{b, d}$ & 2.53 & & \\
\hline & HS & 10 & $18.01^{\mathrm{a}}$ & 4.07 & & \\
\hline & A & 10 & $6.81^{c}$ & 2.66 & & \\
\hline & AS & 10 & $8.55^{c, d}$ & 3.27 & & \\
\hline & C & 10 & $5.37^{c}$ & 1.68 & & \\
\hline & CS & 10 & $5.37^{\mathrm{c}}$ & 2.64 & & \\
\hline & $S$ & 10 & $5.36^{c}$ & 1.74 & & \\
\hline \multirow{8}{*}{ VS } & $\mathrm{K}$ & 10 & $3.43^{c, d}$ & 1.97 & \multirow{8}{*}{11.709} & \multirow{8}{*}{0.001} \\
\hline & $\mathrm{H}$ & 10 & $12.84^{\mathrm{a}}$ & 4.37 & & \\
\hline & HS & 10 & $11.6^{\mathrm{a}}$ & 3.09 & & \\
\hline & A & 10 & $8.7^{\mathrm{a}, \mathrm{b}}$ & 3.04 & & \\
\hline & AS & 10 & $7.15^{b, c}$ & 4.15 & & \\
\hline & C & 10 & $5.62^{b, c}$ & 2.31 & & \\
\hline & CS & 10 & $5.99^{b, d}$ & 2.54 & & \\
\hline & $S$ & 10 & $4.3^{c, d}$ & 2.6 & & \\
\hline \multirow{8}{*}{ VE } & $\mathrm{K}$ & 10 & $8.87^{b}$ & 5.25 & \multirow{8}{*}{2.461} & \multirow{8}{*}{0.025} \\
\hline & $\mathrm{H}$ & 10 & $13.17^{a, b}$ & 1.9 & & \\
\hline & HS & 10 & $14.5^{\mathrm{a}, \mathrm{b}}$ & 3.33 & & \\
\hline & $A$ & 10 & $12.65^{a, b}$ & 5.22 & & \\
\hline & AS & 10 & $11.25^{a, b}$ & 4.64 & & \\
\hline & C & 10 & $13.99^{a, b}$ & 4.69 & & \\
\hline & CS & 10 & $16.25^{a}$ & 5.83 & & \\
\hline & $S$ & 10 & $10.59^{a, b}$ & 5.82 & & \\
\hline \multirow{8}{*}{ NH } & $K$ & 10 & $5.53^{b}$ & 1.37 & \multirow{8}{*}{7.506} & \multirow{8}{*}{0.001} \\
\hline & $\mathrm{H}$ & 10 & $12.81^{\mathrm{a}}$ & 4.03 & & \\
\hline & HS & 10 & $12.44^{\mathrm{a}}$ & 3.43 & & \\
\hline & $A$ & 10 & $5.76^{b}$ & 2.08 & & \\
\hline & AS & 10 & $8.24^{a, b}$ & 3.3 & & \\
\hline & C & 10 & $8.23^{a, b}$ & 2.41 & & \\
\hline & CS & 10 & $8.26^{a, b}$ & 3.64 & & \\
\hline & $S$ & 10 & $8.69^{a, b}$ & 3.49 & & \\
\hline
\end{tabular}

*Tukey HSD test, there is no statistically significant difference between the mean SBS values of the groups with common lowercase letters ( $p>0.05)$. 
Table 4. Failure modes of the experimental groups

\begin{tabular}{|c|c|c|c|c|c|c|c|c|c|c|c|}
\hline & & \multicolumn{8}{|c|}{ FAILURE MODE } & \multicolumn{2}{|c|}{ Chi Square Test } \\
\hline & & \multicolumn{2}{|c|}{ Type 1} & \multicolumn{2}{|c|}{ Type 2} & \multicolumn{2}{|c|}{ Type 3} & \multicolumn{2}{|c|}{ Total } & \multirow[b]{2}{*}{ Chi Square } & \multirow[b]{2}{*}{$p$} \\
\hline & & $n$ & $\%$ & n & $\%$ & $\mathbf{N}$ & $\%$ & $n$ & $\%$ & & \\
\hline \multirow{5}{*}{ Materials } & $C D$ & 51 & 26.29 & 29 & 29.9 & 0 & 0 & 80 & 25 & \multirow{5}{*}{94.296} & \multirow{5}{*}{0.001} \\
\hline & VS & 47 & 24.23 & 33 & 34.02 & 0 & 0 & 80 & 25 & & \\
\hline & VE & 43 & 22.16 & 9 & 9.28 & 28 & 96.55 & 80 & 25 & & \\
\hline & NH & 53 & 27.32 & 26 & 26.8 & 1 & 3.45 & 80 & 25 & & \\
\hline & Total & 194 & 100 & 97 & 100 & 29 & 100 & 320 & 100 & & \\
\hline \multirow{9}{*}{$\begin{array}{l}\text { Surface } \\
\text { Treatments }\end{array}$} & K & 38 & 19.59 & 2 & 2.06 & 0 & 0 & 40 & 12.5 & \multirow{9}{*}{$*$} & \multirow{9}{*}{0.001} \\
\hline & $\mathrm{H}$ & 27 & 13.92 & 12 & 12.37 & 1 & 3.45 & 40 & 12.5 & & \\
\hline & HS & 12 & 6.19 & 20 & 20.62 & 8 & 27.59 & 40 & 12.5 & & \\
\hline & A & 25 & 12.89 & 12 & 12.37 & 3 & 10.34 & 40 & 12.5 & & \\
\hline & AS & 20 & 10.31 & 15 & 15.46 & 5 & 17.24 & 40 & 12.5 & & \\
\hline & C & 21 & 10.82 & 13 & 13.4 & 6 & 20.69 & 40 & 12.5 & & \\
\hline & CS & 13 & 6.7 & 21 & 21.65 & 6 & 20.69 & 40 & 12.5 & & \\
\hline & S & 38 & 19.59 & 2 & 2.06 & 0 & 0 & 40 & 12.5 & & \\
\hline & Total & 194 & 100 & 97 & 100 & 29 & 100 & 320 & 100 & & \\
\hline
\end{tabular}

*Chi-Square Analysis, Chi-square analysis was performed with the Monte Carlo Simulation since $20 \%$ of the expected value in cells is less than 5.

\section{DISCUSSION}

This in vitro study evaluated the effect of different surface treatments on the SR and SBS of resin cement to/on? different CAD/CAM ceramic materials and demonstrated that the surface treatment methods have an influence on SR and SBS test values of the materials used and that these surface treatment methods significantly affected the results of this study. Consequently, the results of this study reject both null hypotheses.

Lithium-silicate based glass ceramics and hybrid ceramics have been recently used as materials for CAD/CAM techniques $(5,6)$. The newest generation glass ceramics VS and $C D$ contains $10 \%$ wt. highly dispersed zirconia $(9,11)$. One of the two hybrid ceramics used in this study is a ceramic network consisting of approximately $14 \%$ resin embedded in $86 \%$ of a ceramic network VE material $(15,21,26,33)$. Another new CAD/CAM hybrid ceramic is the NH material for permanent restorations and contains 50\% nano-glass and $50 \%$ polymer-matrix. This new hybrid ceramic has been introduced for manufacturing partial crowns, veneers and up to 3 units bridges (34).

To evaluate the adhesion of resin cement, tensile and micro tensile bond strength, pull and push tests are the other test methods. Sano et al. created the micro tensile bond strength test in order to eliminate the non-uniform stress distribution within the adhesive zone (35). However, the micro tensile bond strength test method is difficult to conduct, time consuming and highly technique sensitive because of the specimen preparation (28). The SBS test is simple and reliable. Hu et al. compared the difference between the two SBS tests for resin composite cements and concluded that the shear test is reliable to assess differences in bonding performance as long as shearing occurs at the interface with no fracture of the substrate (29). Therefore, the SBS test was used in the present study.
Achieving a chemical adhesion at the cement/ceramic interface may be essential for successful full bonds. Cement selection is a precondition for ensuring effective bond strength to indirect restorations. It has been found that bond strength is more effective when using dual-cured resin cement in indirect restorations (32). In the present study, only one resin cement was used to ensure standardization.

Various surface treatment techniques are preferred depending on the characteristics of the material $(32,37)$. Elsaka SE has evaluated and confirmed the effect of surface treatments applied to CAD / CAM materials on micro tensile bond strength to resin cement (32). Similar results have also been reported for glass ceramics (26). Also, Kim et al. stated that the bonding strength varies between different types of materials even when implementing the same surface treatment method (24). In this study, different surface treatments were applied to different CAD/CAM material surfaces and SR and SBS values of the treated surfaces were evaluated. An important requirement for the clinically successful function of ceramic indirect restorations is adequate adhesion between the ceramic and tooth structure and the surface treatment prior to cementation could enhance the bond strength (38). Common physical surface treatment methods are roughening with a diamond bur, airborne particle abrasion with alumina or silica and etching with hydrofluoric acid (HF) (4). During HF etching, parts of the silicate ceramic surface are etched and result in the surface roughness. The HF etching time is important for adequate mechanical retention $(4,20)$. Della Bona et al. suggested that etching mechanisms change according to the type of the etchant and etching time and the ceramic microstructure and composition (39). In another study, Menees et al. found that $\mathrm{HF}$ etching for 20 seconds in concentrations varying from $5 \%$ and $9.5 \%$ is enough for etching. (40). In another study, Sato et al. concluded that etching with HF acid for 20 and 40 seconds was equally effective in producing stable resin bonding to a 
zirconia reinforced lithium silicate ceramic (12). Therefore, $5 \% \mathrm{HF}$ acid was applied for 20 seconds in the present study.

Airborne abrasion using alumina or silica particles is commonly recommended for luting resin composites to $\operatorname{CAD} / \operatorname{CAM}$ blocks $(4,21,25)$. The air abrasion system ensures air-particle abrasion with different particle sizes ranging from 30 to 250 micron between the ceramic and cement $(41,42)$. Generally, sand blasting pressure is recommended as 0.1 $0.2 \mathrm{MPa}$. However, this pressure is lower than the pressure commonly used for ceramic restorations (25). In the present study, the surfaces were sandblasted in the air abrasion groups at 2.5 bars. The SR of the material was evaluated with a surface profilometer. In this study, Ra, which is the mean value of all absolute distances of the linear roughness profile, was used (43).

Regarding the influence of surface treatments between the four CAD/CAM materials, the A and AS groups produced significantly higher Ra values compared to the others and followed by the $\mathrm{C}$ and $\mathrm{CS}$ groups significantly. Untreated group $\mathrm{K}$ and $\mathrm{S}$ surfaces showed generally the lowest roughness values. In the present study, $\mathrm{NH}$ material showed the highest Ra values in A and AS groups followed by VE materials. Then, among the treated surfaces, the lowest values were observed in $\mathrm{H}$ and $\mathrm{HS}$ groups. Both $\mathrm{NH}$ and VE materials are hybrid ceramics and have different microstructures. The moduli of elasticity of $\mathrm{NH}$ and VE materials are $9.9 \mathrm{GPa}$ and $30.0 \mathrm{GPa}$ according to the manufacturer's information (34, 44). The composition of the NH new hybrid ceramic material matrix consists of $50 \%$ nano glass and $50 \%$ polymer matrix. According to the manufacturer's information, $100 \%$ silanized glass is permanently integrated into the polymer matrix (34). VE is based on a polymer-infiltrated ceramic network material that consists of a dominant network (86 wt.\%) reinforced by an acrylic polymer network (14\%). The two networks penetrate each other completely (45). This could possibly be attributed to the different compositions of these two hybrid ceramics with different filler contents, which have an impact on the much higher SR values. According to the SBS test results for the different tested materials, the $\mathrm{H}$ and $\mathrm{HS}$ chemical conditioning groups produced the highest bond strength values contrary to the SR test results.

Although the SR of the materials is high in A and AS groups in the present study, generally the highest SBS values were observed on $\mathrm{H}$ and $\mathrm{HS}$ treated surfaces. The lowest SR values in $\mathrm{H}$ and $\mathrm{HS}$ groups were found in VE and CS materials, but also the highest SBS values.

According the SBS results, $\mathrm{H}$ and HS treated surfaces produced the highest bond strength and the highest values were observed on the $\mathrm{CD}$ material $(18.01 \pm 4.07 \mathrm{MPa})$ in the $\mathrm{H}$ group and followed by the VE material $(16.25 \pm 5.83 \mathrm{MPa})$ in the CS treatment group. Both ceramics are etchable ceramics. Then, these materials were followed by the VE material $(14.5 \pm 3.33 \mathrm{MPa})$ in the HS group, VS material $(12.84 \pm 4.37$ $\mathrm{MPa}$ ) in the $\mathrm{H}$ group and $\mathrm{NH}$ material $(12.81 \pm 4.03 \mathrm{MPa})$ in $\mathrm{H}$ and $(12.44 \pm 3.43) \mathrm{HS}$ groups. As surface treatments, Frankenberger et al. suggested using HF acid for the VE material and also lithium disilicate ceramics. (46). In another study, Aboushelib et al. investigated the effect of surface treatments of two types of lithium disilicate ceramics on the micro tensile bond strength to a resin adhesive and found that the highest strength values were observed significantly in the $\mathrm{CD}$ material (34 MPa), which were also used and found in the present study (10). Also, they concluded that bond strength to lithium disilicate ceramics depends on proper surface treatment and on the chemical composition of the glass ceramics. Their bond strength methodology was not exactly the same as we used in this study, there was no micro tensile bond strength, but we used the SBS test. So, direct comparisons are not applicable. Sato et al. evaluated the effect of surface conditioning of the zirconia reinforced lithium silicate ceramic and resin cement on the micro tensile bond strength and observed that the silica coating was not efficient and etching with hydrofluoric acid for 20 seconds was effective for the stable resin bonding (12). In another study, Al-Thagaafi et al. (47) investigated the effect of surface conditioning protocols on the VS zirconia reinforced lithium silicate ceramic material with micro tensile bond strength and found that the bond strength of VS was $31.2 \mathrm{MPa}$ in the HS treatment group and also has the highest bond strength values in sandblasting with Cojet sand. Pneumans et al. and Elsaka et al. investigated the micro tensile bonding performance of different glass ceramics and resin cement $(11,32)$. Pneumans et al. used $\mathrm{H}$ acid etching (\%5) and silane combination as the surface treatment and they found that the best pretreatment for C (41.5) and VE (46.3) materials included etching with HF acid and observed that an application of $\mathrm{S}$ did not have any effect on the bond strength values (11). In contrast to the study of Pneumans et al., we observed the highest SBS values for the CD material in the $\mathrm{HS}$ (18.01 MPa) group compared to the $\mathrm{H}$ group (11.58 MPa). Elsaka et al. found the highest SBS value for the VE material (27.4 MPa) (32). The HS group showed higher values of bond strength compared to other treated surfaces, and the specimens including cohesive failure failed in a mixed mode. In this study, among all tested materials, the failure mode for the VE material was found between all tested materials the highest percentage of mixed cohesive failure. For CD and VS glass ceramics were observed more adhesive and cohesive mixed failures. Another published investigation measured the micro bond strength values of VE and CD materials and found 20.2 and 26.9 MPa (46). Both values are very close to the results of the present study in the HS group. Various in vitro studies established that $\mathrm{H}$ acid etching in combination with the use of silane is the finest surface treatment for lithium disilicate glass ceramics and the zirconia reinforced lithium silicate ceramics $(11,48,49)$. According to the results of this study, as surface roughness increased through mechanical surface treatment as A or C, air-particle abrasion had less impact on the SBS test than chemical conditioning.

Concerning the mechanical bond strength, the present study used the SBS method to investigate the bond strength between different glass ceramic materials and resin cement. $\mathrm{Hu}$ et al. (29) evaluated and compared the adhesion of 
different-cement combinations with the SBS test The VS material $(21.6 \mathrm{MPa})$ they found in the glass-based ceramic groups revealed significantly higher values than the VE material (14.7 MPa), and they also observed that on etched surfaces, VE exhibited primarily cohesive failures and the VS material exhibited primarily adhesive failures. According to the results of this study, considering all surface treatments, while adhesive and cohesive failures were found in the VS material, adhesive and primarily cohesive failures were observed in the VE material. This result was in accordance with the results of $\mathrm{Hu}$ et al and Elsaka et al. (29. 32). Also, similarly, some studies investigated the effect of the SBS test on hybrid ceramics $(14,30)$. Gungor et al. concluded that SBS was affected by surface treatments and found strength values for the VE material in HS treatment groups as 17.91 MPa (30).

Rohr et al. observed the highest SBS values for the VE material as 11.5 MPa and Schwenter et al. as 19.9 MPa. Similar results were obtained in the present study, which was in agreement with previous studies $(14,16,20,29,30)$. In the present study, the highest SBS value with the VE material was determined in the CS group as $16.25 \pm 5.83 \mathrm{MPa}$, not in the HS group. VE with CS treatment showed comparable bond strength to HS. This result is in agreement with previous studies $(26,32)$. In the study by Campos et al., $C$ treatment group also resulted in the highest bond on the VE material before aging, but micro tensile bond strength values decreased significantly after aging (26). According to the study of Elsaka et al., for the groups etched with $\mathrm{H}$ and $\mathrm{HS}$, the SR was lower than A, AS treatments, but the higher bond strength on the nonaged group for the VE material was found in the HS group and were comparable with the AS group (32).

Between the surface treatment groups, most of the specimens in the HS group showed mixed and primarily cohesive failures according to the present study and also the failure mode may also change with different tested material types. (32). The adhesive type of failure is typically associated with low bond strength values. Thus, mixed and cohesive failure modes are clinically preferable to total adhesive failure (50). Therefore, this finding is valuable data on the performance of the ceramic-resin bond where the resin cement is chemically bonded to the substrate material (20). Several studies reported mean SBS values between 15-25 MPa among the glass ceramic and resin for clinical applications, which is in agreement with the present SBS values data $(14,16,20,29$, 30).

In this study, a single type of resin cement and silane coupling agent were used to ensure standardization. However, the sort of luting agent is the main determinant in the adhesion of dental materials.

Another limitation of the study is that thermal cycling was not included. Specimens in water at $37 \mathrm{C}^{0}$ were only shortterm storage. Future in vitro studies should be conducted to investigate other factors such as different resin cement. Silane coupling agents and different test methodology should involve aging conditions together with the use of thermocycling to provide a closer simulation of clinical situations.

\section{CONCLUSION}

With the limitations of this in vitro study, these conclusions can be emphasized:

In the present study, surfaces with A and AS treated groups increased the SR for all tested ceramics and are significantly followed by the $\mathrm{C}$ and CS surface treated groups.

Among all ceramic materials, the highest SBS values were observed in the HS group on the CD material and in the CS group on the VE material and in $\mathrm{H}$ and HS surface treatment groups on the VS and $\mathrm{NH}$ materials. The failure mode for $\mathrm{CD}$ and VS and NH materials was found to be the highest percentage adhesive and cohesive failures, however, adhesive and mixed cohesive failure was primarily observed for the VE material.

3. The higher SR will not always provide a higher bond strength value. SBS test results depend on the effect of surface treatments on the bond strength of the tested materials to resin cement.

\section{Acknowledgment}

This study was supported by the grant no. 03/2017-24 from Scientific Research Project of the Rectorship of Gazi University

\section{Conflicts of interest}

The authors declare that they have no conflict of interest

\section{REFERENCES}

[1] Della Bona A, Corazza PH, Zhang Y. Characterization of a polymer-infiltrated ceramic-network material. Dent Mater 2014; 30:564-569.

[2] Albero A, Pascual A, Camps I, Grau-Benitez M.J. Comparative characterization of a novel cad-cam polymer-infiltratedceramic-network. Clin Exp Dent 2015; 7: e495-500.

[3] Pisani-Proenca J, Erhardt MC, Valandro LF, Gutierrez-Aceves G, Bolanos-Carmona MV, Del Castillo-Salmeron R, Bottino MA. Influence of ceramic surface conditioning and resin cements on microtensile bond strength to a glass ceramic. J Prosthet Dent 2006; 96:412-417.

[4] Blatz MB, Sadan A, Kern M. Resin-ceramic bonding: a review of the literature. J Prosthet Dent 2003; 89:268-274.

[5] Denry I, Kelly JR. Emerging ceramic-based materials for dentistry. J Dent Res 2014; 93:1235-42.

[6] Gracis S, Thompson VP, Ferencz JL, Silva NR, Bonfante EA. A new classification system for all-ceramic and ceramic-like restorative materials. Int J Prosthodont 2015; 28:227-235.

[7] Beuer F, Stimmelmayr M, Gueth JF, Edelhoff D, Naumann M. In vitro performance of full-contour zirconia single crowns. Dent Mater 2012; 28:449-456.

[8] Sun T, Zhou S, Lai R, Liu R, Ma S, Zhou Z, Longquan S. Loadbearing capacity and the recommended thickness of dental 
monolithic zirconia single crowns. J Mech Behav Biomed Mater 2014; 35:93-101.

[9] Elsaka SE, Elnaghy AM. Mechanical properties of zirconia reinforced lithium silicate glass-ceramic. Dent Mater 2016; 32:908-914.

[10] Aboushelib MN, Sleem D. Microtensile bond strength of lithium disilicate ceramics to resin adhesives. J Adhes Dent 2014; 16:547-552.

[11] Pneumans M, Valjakova EB, Munck JD, Mishevska CB, Meerbeek BV. Bonding effectiveness of luting composites to different CAD/CAM materials. J Adhes Dent 2016; 18:289-302.

[12] Sato TP, Anami LC, Melo RM, Valandro LF, Bottino MA. Effects of surface treatments on the bond strength between resin cement and a new zirconia-reinforced lithium silicate ceramic. Oper Dent 2016; 41:284-292.

[13] Chen C, Trindade FZ, de Jager N, Kleverlaan CJ, Feilzer AJ. The fracture resistance of a CAD/CAM Resin Nano Ceramic (RNC) and a CAD ceramic at different thicknesses. Dent Mater 2014; 30:954-962.

[14] Rohr N, Flury A, Fischer J. Efficacy of a universal adhesive in the bond strength of composite cements to polymer-infiltrated ceramic. J Adhes Dent 2017; 19:417-424.

[15] Bellan MC, Cunha PFJSD, Tavares JG, Spohr AM, Mota EG. Microtensile bond strength of CAD/CAM materials to dentin under different adhesive strategies. Braz Oral Res 2017; 31:e109.

[16] Ustun O, Buyukhatipoglu IK, Secilmiş A. Shear bond strength of repair systems to new CAD/CAM Restorative Materials. J Prosthodont 2018; 27:748-754.

[17] Stawarczyk B, Krawczuk A, Ilie N. Tensile bond strength of resin composite repair in vitro using different surface preparation conditionings to an aged CAD/CAM resin nanoceramic. Clin Oral Investig 2015; 19:299-308.

[18] Mainjot AK, Dupont NM, Oudkerk JC, Dewael TY, Sadoun MJ. From artisanal to CAD-CAM bocks: State of the art of indirect composites. J Dent Res 2016; 95:487-495.

[19] Wong ACH, Tian T, Tsoi JKH, Burrow MF, Matinlinna JP. Aspects of adhesion tests on resin-glass ceramic bonding. Dent Mater 2017; 33:1045-1055.

[20] Schwenter J, Schmidli F, Weiger R, Fischer adhesive bonding to polymer infiltrated ceramic. Dent Mater J 2016; 35:796-802.

[21] Diaz-Arnold AM, Vargas MA, Haselton DR. Current status of luting agents for fixed prosthodontics. J Prosthet Dent 1999; 81:135-141.

[22] Mair L, Padipatvuthikul P. Variables related to materials and preparing for bond strength testing irrespective of the test protocol. Dent Mater 2010; 26: e17-23.

[23] Della Bona A, Shen C, Anusavice KJ. Work of adhesion of resin on treated lithia disilicate-based ceramic. Dent Mater 2004; 20:338-344

[24] Kim JE, Kim JH, Shim JS, Roh BD, Shin Y. Effect of air-particle pressures on the surface topography and bond strengths of resin cement to the hybrid ceramics. Dent Mater J 2017; 36:454-460.

[25] Yoshihara K, Nagaoka N, Maruo Y, Nishigawa G, Irie M, Yoshida Y, Van Meerbeek B. Sandblasting may damage the surface of composite CAD-CAM blocks. Dent Mater 2017; 33:e124-e135.

[26] Campos F, Almeida CS, Rippe MP, de Melo RM, Valandro LF, Bottino MA. resin bonding to a hybrid ceramic: effects of surface treatments and aging. Oper Dent 2016; 41:171-178.
[27] Ozcan M, Vallittu PK. Effect of surface conditioning methods on the bond strength of luting cement to ceramics. Dent Mater 2003; 19:725.

[28] Pollington S, Fabianelli A, van Noort R. Microtensile bond strength of a resin cement to a novel fluorcanasite glassceramic following different surface treatments. Dent Mater 2010; 26:864-872.

[29] $\mathrm{Hu}$ M, Weiger R, Fischer J. Comparison of two test designs for evaluating the shear bond strength of resin composite cements. Dent Mater 2016; 32:223-232.

[30] Güngör MB, Nemli SK, Bal BT, Ünver S, Doğan A. Effect of surface treatments on shear bond strength of resin composite bonded to CAD/CAM resin-ceramic hybrid materials.J Adv Prosthodont 2016; 8:259-266.

[31] Heintze SD, Zimmerli B. Relevance of in vitro tests of adhesive and composite dental materials. A review in 3 parts. Part 3: in vitro tests of adhesive systems. Schweiz Monatsschr Zahnmed 2011; 121:1024-1040.

[32] Elsaka SE. Bond strength of novel CAD/CAM restorative materials to self-adhesive resin cement: the effect of surface treatments. J Adhes Dent 2014; 16:531-540.

[33] Spitznagel FA, Horvath SD, Guess PC, Blatz MB. Resin bond to indirect composite and new ceramic/polymer materials: a review of the literature. J Esthet Restor Dent 2014; 26:382393.

[34] https://c4d.solutions/wp-content/uploads/2019/02/dmchybrid-anleitung-webseite en-1.pdf

[35] Sano H, Shono T, Sonoda H, Takatsu T, Ciucchi B, Carvalho R, Pashley $\mathrm{DH}$. Relationship between surface area for adhesion and tensile bond strength-evaluation of a micro-tensile bond test. Dent Mater 1994; 10:236-240.

[36] Ozcan M, Nijhuis H, Valandro LF. Effect of various surface conditioning methods on the adhesion of dual-cure resin cement with MDP functional monomer to zirconia after thermal aging. Dent Mater J 2008; 27:99-104.

[37] Lise DP, Van Ende A, De Munck J, Vieira L, Baratieri LN, Van Meerbeek B. Microtensile Bond Strength of Composite Cement to Novel CAD/CAM Materials as a Function of Surface Treatment and Aging. Oper Dent 2017; 42:73-81.

[38] Peumans M, Hikita K, De Munck J, Van Landuyt K, Poitevin A, Lambrechts P, Van Meerbeek B. Effects of ceramic surface treatments on the bond strength of an adhesive luting agent to CAD-CAM ceramic. J Dent 2007; 35:282-288.

[39] Della Bona A, Anusavice KJ. Microstructure, composition, and etching topography of dental ceramics. Int J Prosthodont 2002; 15:159-167.

[40] Menees TS, Lawson NC, Beck PR, Burgess JO. Influence of particle abrasion or hydrofluoric acid etching on lithium disilicate flexural strength. J Prosthet Dent 2014; 112:11641170 .

[41] Amaral R, Ozcan M, Bottino MA, Valandro LF. Microtensile bond strength of a resin cement to glass infiltrated zirconiareinforced ceramic: the effect of surface conditioning. Dent Mater 2006; 22:283-290.

[42] Ozcan M. Evaluation of alternative intra-oral repair techniques for fractured ceramic-fused-to-metal restorations. J Oral Rehabil 2003; 30:194-203.

[43] Whitehead SA, Shearer AC, Watts DC, Wilson NH. Comparison of methods for measuring surface roughness of ceramic. J Oral Rehabil 1995; 22:421-427. 
[44] Homaei E, Farhangdoost K, Tsoi JKH, Matinlinna JP, Pow EHN. Static and fatigue mechanical behavior of three dental CAD/ CAM ceramics. J Mech Behav Biomed Mater 2016; 59:304313.

[45] Zimmermann M, Mehl A, Reich S. New CAD/CAM materials and blocks for chairside procedures. Int J Comput Dent 2013; 16:173-181.

[46] Frankenberger R, Hartmann VE, Krech M, Krämer N, Reich S, Braun A, Roggendorf $M$. Adhesive luting of new CAD/CAM materials. Int J Comput Dent 2015; 18:9-20.

[47] Al-Thagafi R, Al-Zordk W, Saker S. Influence of surface conditioning protocols on reparability of CAD/CAM zirconia-reinforced lithium silicate ceramic. J Adhes Dent 2016; 18:135-141.

[48] Lise DP, Perdigão J, Van Ende A, Zidan O, Lopes GC. Microshear bond strength of resin cements to lithium disilicate substrates as a function of surface preparation. Oper Dent 2015; 40:52432.

[49] Özcan M, Volpato CA. Surface conditioning protocol for the adhesion of resin-based materials to glassy matrix ceramics: How to condition and why? J Adhes Dent 2015; 17:292-293.

[50] Oyagüe RC, Monticelli F, Toledano M, Osorio E, Ferrari M, Osorio R. Effect of water aging on microtensile bond strength of dual-cured resin cements to pre-treated sintered zirconiumoxide ceramics. Dent Mater 2009; 25:392-399.

How to cite this article: Sevmez H, Yilmaz H. Comparison of the Effect of Surface Conditioning Methods on the Bond Strength of Different Zirconia Reinforced Lithium Silicate and Hybrid Ceramics to Resin Cement. Clin Exp Health Sci 2021; 11: 554-563. DOI: 10.33808/clinexphealthsci.867710 